\title{
Processos políticos e a produção de papéis e significados: uma análise das relações entre o Estado e o movimento LGBT na criação do Centro de Referência GLTTB de Campinas - SP
}

\author{
Vinícius Pedro Correia Zanoli*
}

\begin{abstract}
Resumo: 0 presente artigo tem como foco a análise do processo político que levou à criação do Centro de Referência GLTTB de Campinas, primeira política pública a oferecer assistência social, jurídica e psicológica a LGBT no Brasil. Assim sendo, serão enunciados os atores envolvidos, privilegiando as relações estabelecidas entre aqueles pertencentes ao Estado e ao movimento LGBT. A análise recai sobre a produção relacional e processual de categorias simbólicas através das quais atores sociais presentes em processos políticos locais compreendem sua ação política, isto é, seu discurso acerca de sua ação política. Evidenciando assim os múltiplos pertencimentos institucionais dos atores envolvidos no processo político aqui tratado, bem como, a porosidade das fronteiras entre Estado e movimento LGBT, colaborando para a crítica a análise que toma tais entidades como discretas e homogêneas.
\end{abstract}

Palavras-chave: movimento LGBT, Estado, homossexualidade, movimentos sociais, políticas públicas.

Este artigo trata de um processo político local, datado da década de 2000, que envolveu atores ligados ao movimento LGBT, a outros movimentos sociais e ao Estado: a criação do Centro de Referência GLTTB de Campinas, inaugurado em 2003, primeira política pública a oferecer assistência social, jurídica e psicológica a essa população no Brasil. Para tal, apresento os atores sociais envolvidos no processo e suas relações.

Foram privilegiadas as relações estabelecidas entre atores provenientes do ativismo em torno dos direitos de $\mathrm{LGBT}^{1}$ e o Estado.

O objetivo é analisar a produção relacional e processual de categorias simbólicas através das quais atores sociais presentes no processo em questão compreendem sua ação política.

\footnotetext{
*Graduando em Ciências Sociais - UNICAMP. Bolsista de iniciação científica sob orientação da Profª . Drª - Regina Facchini, com apoio da FAPESP, no Núcleo de Estudos de Gênero, Pagu, da mesma Universidade.

${ }^{1}$ A sigla LGBT se refere ao movimento político organizado em torno do direito de lésbicas, gays, bissexuais, travestis e transexuais. Sua escolha foi votada na I Conferencia Nacional LGBT, em 2008 (FACCHINI; FrAnçA, 2009).
} 
A pesquisa, na qual se baseia este artigo, tem caráter etnográfico, agregando observação e entrevistas. A observação ocorreu entre os meses de agosto de 2010 e agosto de 2012. Foram observados: (a) os grupos ativistas LGBT de Campinas, especialmente os membros do Identidade, em atividades realizadas pelos ativistas e nas Paradas do Orgulho LGBT da cidade; e (b) os gestores públicos ligados ao Centro de Referência e à Coordenadoria de Políticas para a Diversidade nas atividades que organizaram. 0 material conta, ainda, com dez entrevistas provenientes de oito interlocutores.

A cidade escolhida para a realização da pesquisa foi Campinas com população estimada, segundo o IBGE ${ }^{2}$, em pouco mais de um milhão de habitantes. Portanto, uma cidade do interior de grande porte. 0 município é, ainda, sede da Região Metropolitana de Campinas.

\section{O surgimento do Movimento LGBT brasileiro e seus primeiros passos em Campinas}

O movimento LGBT teve seu início no Brasil em 1978, com a criação do grupo Somos de São Paulo (Macrae, 1990; Green, 2000; Simões; FACChInI, 2009; FACCHINI, 2009). Ao periodizar a trajetória desse movimento a partir do contexto político no qual se insere, problematizando de que maneira as organizações ativistas se relacionam com os demais atores sociais presentes em seu "campo" de ativismo, Facchini (2005) aponta para a existência de três "ondas" do movimento.

A "primeira onda" é marcada pelo surgimento do Grupo Somos de São Paulo (MACRAE, 1990). A segunda, pelo declínio do número de grupos e pela epidemia de HIV/Aids na década de 1980. Um dos principais representantes dessa fase é o Triângulo Rosa do Rio de Janeiro (CÂMARA, 2002). A partir dos anos 1990, o movimento passa pela sua "terceira onda".

Nesse último período, o movimento LGBT passa por um processo de institucionalização, tornando-se um dos mais visíveis no cenário político nacional. Em decorrência desse processo, muitos grupos passaram a assumir o formato de ONGs, fenômeno que, como esclarece Doimo (1995), não é apenas característico do movimento LGBT. Com a redemocratização, outros movimentos sociais se

\footnotetext{
${ }^{2}$ Informações provenientes do site IBGE cidades. Disponível em: < http://www.ibge.gov.br/cidadesat/ topwindow.htm?1>. Acesso: $5 \mathrm{dez} 2012$.
} 
institucionalizaram, assumindo formato de organizações não governamentais, registrando sua existência em cartório com a criação de estatutos e participando de editais públicos.

É na terceira "onda" do movimento, que surge o Expressão, primeiro grupo ativista LGBT de que se tem notícia em Campinas. 0 coletivo foi fundado em 1995 e era responsável pela edição de um jornal, "O Babado", que circulava em espaços de sociabilidade homossexual da cidade. Os fundadores do Expressão frequentavam um grupo de vivência no âmbito do Programa Municipal de DST/Aids, o Conviver. Em 1995, depois de uma palestra oferecida por Luiz Mott $^{3}$ na Unicamp, frequentadores do Conviver criaram o Expressão.

Em 1998, a partir de uma cisão do Expressão, surge o Identidade. 0 motivo dessa cisão está ligado à edição d' "O Babado". O setor do Expressão que mais tarde fundaria o Identidade, considerando que deveria dialogar mais com as lésbicas, decidiu estampar um casal de mulheres na capa do jornal de março de 1998. Pretendiam que essa edição focalizasse a temática lésbica, visto a proximidade do 8 de março. Entretanto, contrariando negociações prévias, sem aviso, o conteúdo do jornal foi modificado pela parcela do grupo considerada majoritária no Expressão, minimizando o enfoque dado às lésbicas. Isso causou grande revolta no setor do Expressão que viria a se tornar Identidade. Ainda que, de última hora, o jornal tenha sido editado da maneira inicialmente prevista, essa situação causou desgaste entre os integrantes do grupo (ZANOLI; FACCHINI, 2012).

O evento que deu origem ao Identidade, ou seja, a disputa em torno da edição d' "O Babado", não pode ser visto como um momento isolado que causou por si só a cisão do grupo. Ao olhar para o que os ativistas que deixaram o Expressão alegam ser o motivo que os levou a fazer isso, ou seja, o caráter mais festivo e menos preocupado com questões políticas do grupo, vemos que esse evento expressa uma tensão pré-existente, que diz respeito à própria concepção de política de duas parcelas da organização militante. Desse modo, o Identidade foi fundado em decorrência de uma diferença na concepção do que seria o papel de um movimento social, e do que seria política, tornando a coexistência de facções vistas como antagônicas impossível

\footnotetext{
${ }^{3}$ Mott é um antropólogo e importante ativista da causa LGBT na Bahia.
} 
dentro de um mesmo grupo. Isso teria motivado essa parcela crítica da atuação do Expressão a fundar um novo coletivo de homossexuais ${ }^{4}$ no dia 19 de maio de 1998.

O Identidade é o grupo ativista LGBT em atividade mais antigo de Campinas. Apenas dois anos após sua fundação, em 2000, o grupo se dividiu, essa divisão deu origem ao Mo.Le.Ca. (Movimento Lésbico de Campinas). No início dos anos 2000, esses dois grupos eram os mais atuantes no cenário LGBT do município. Feita a contextualização histórica do movimento LGBT em âmbito nacional e esboçada a trajetória do movimento campineiro até o início da década de 2000, passemos ao processo político local que é central a esta análise.

\section{Conflitos e disputas na implementação do Centro de Referência}

No processo eleitoral de 2000, o candidato Antônio da Costa Santos, o Toninho do PT, apresenta como proposta de campanha a implementação de um Orçamento Participativo, ferramenta de gestão que convida a sociedade civil a opinar e participar na avaliação e proposição de políticas para o município.

Com sua eleição ano seguinte, 2001, Toninho inicia a criação da nova política de gestão através de reuniões nas quais foram criados eixos temáticos em que determinados setores prioritários da sociedade civil organizada discutiriam questões específicas - a saber: saúde, assistência, cidadania, cultura e esporte, desenvolvimento econômico, educação e gestão. Algumas dessas temáticas eram também divididas em categorias. Em princípio, no entanto, o movimento LGBT não foi convidado a participar em nenhum dos eixos temáticos, diferentemente de outros movimentos, como as mulheres e os deficientes físicos, por exemplo ${ }^{5}$.

Como principais representantes do movimento LGBT em Campinas, o Identidade e o Mo.Le.Ca., inconformados com a exclusão dos LGBT, deram início ao que denominam processo de luta pela inclusão dos homossexuais no OP. Tal processo foi marcado por negociações entre os grupos ativistas LGBT da cidade e representantes do executivo municipal. Segundo os entrevistados, nas negociações, foi necessário

\footnotetext{
${ }^{4}$ É convenção neste artigo a formatação em itálico quando me referir a categorias êmicas e a pequenas citações referentes à fala de entrevistados ou discursos advindos da observação etnográfica.

${ }^{5} \mathrm{O}$ ano de 2001 foi marcante na história da cidade. No processo de consolidação do OP, o recém-empossado prefeito, Toninho, foi assassinado. Izalene Tiene, sua vice, tomou posse como prefeita e acabou por seguir o caminho de seu antecessor, dando continuidade à criação do OP.
} 
demonstrar a vulnerabilidade e a violação de direitos que sofriam os LGBT enquanto grupo social. 0 processo de luta teve êxito, o que resultou na alocação da categoria homossexual ao eixo temático cidadania do OP, junto aos negros, idosos, jovens, portadores de deficiência e mulheres. A partir daí, com a integração, ainda que trabalhosa, dos grupos homossexuais ao $\mathrm{OP}$, seus representantes poderiam elaborar e encaminhar propostas de políticas públicas.

Com a implementação do OP, em 2002, o movimento LGBT teve aprovada a criação de um Disque-Defesa Homossexual, que acolheria denúncias de crimes homofóbicos. Como resultado das negociações com a Secretaria de Assuntos Jurídicos (SAJ) da cidade, os representantes do movimento LGBT indicaram um ativista (integrante do grupo Identidade) para coordenar o serviço, Lucas ${ }^{6}$.

Ainda em 2002, o movimento LGBT apresentou ao OP o projeto, aprovado no mesmo ano, de criação do Centro de Referência (CR), que ofereceria assistência social, jurídica e psicológica a LGBT. A escrita do projeto envolveu ativistas do Identidade, do Mo.Le.Ca., um ativista do E-Jovem (uma rede jovem LGBT) e uma ativista que mais adiante fundaria o Aos Brados (grupo ativista cujo foco é a atuação "na periferia"). No entanto, de acordo com os entrevistados, mesmo depois de aprovado, o projeto do CR demorou a sair do papel. Essa demora e as dificuldades no processo de negociação desgastaram as relações dos ativistas, principalmente os que faziam parte do Identidade, com o Estado, especialmente com a SAJ.

O principal ponto de tensão foi a demanda do movimento por indicar todos os funcionários da nova política, dado que a proposta fora pensada por eles. Na negociação, o movimento pode indicar a advogada, integrante do Mo.Le.Ca. Além disso, Lucas se tornou também coordenador do CR, o que resultou na incorporação do Disque-Defesa Homossexual ao CR. Os demais funcionários foram contratados através de edital próprio da prefeitura.

Apesar das tensões e das disputas, os ativistas apontam que, foi a partir da participação do OP que puderam compreender o que chamam de morosidade e burocracia estatal. As diversas dificuldades que enfrentaram no caminho e a constante necessidade de cobrança os levaram a lidar melhor ou, pelo menos, saber lidar com

\footnotetext{
${ }^{6}$ Optei por utilizar pseudônimos para me referir a todos os envolvidos no processo político aqui estudado. Procurei, dessa maneira, salvaguardar a identidade dos meus interlocutores.
} 
o Estado. Essa experiência é, portanto, apontada como um aprendizado. 0 reconhecimento desse aspecto positivo da experiência, contudo, não minimizou as críticas ao Estado que resultaram dessas tensões.

$\mathrm{O}$ CR foi inaugurado em 31 de julho de 2003. No período que segue à sua inauguração, as relações de tensão entre movimento e Estado se deslocaram da figura da SAJ para a coordenação do CR. As tensões entre Estado e movimento tornaram o duplo pertencimento institucional insustentável para Lucas, membro-fundador do Identidade e coordenador do CR por indicação do movimento, acarretando no desligamento de sua atuação no grupo Identidade.

Lucas se manteve nesse cargo até o ano de $2010^{7}$, quando, com a criação da Coordenadoria de Políticas para Diversidade Sexual do município, é convidado a coordená-la. Com a transferência do então coordenador do CR para a coordenadoria, a assistente social do centro passa a realizar duas funções, a que já exercia e a de coordenadora do equipamento. A Coordenadoria de Políticas para a Diversidade e o CR estão vinculados à Secretaria de Cidadania da cidade de Campinas. As duas instituições atuam como aliadas por estarem voltadas ao mesmo segmento da população municipal.

No que diz respeito às relações entre os ativistas e os gestores, pude observar um distanciamento gradual entre o Identidade e o CR até 2011. A partir do começo de 2012, parece estar acontecendo uma lenta reaproximação. Contudo, a possibilidade de atuação conjunta ainda é incerta. 0 grupo que, com o passar do tempo, se tornou mais próximo do centro foi o E-Jovem. Uma conhecida drag queen da cidade, e integrante do E-Jovem, é uma das poucas ativistas presentes nos eventos promovidos pelo $\mathrm{CR}$.

O conflito entre movimento LGBT e CR tinha como epicentro ativistas do Identidade e Lucas, ex-ativista e coordenador do CR., por isso, é necessário retomar um pouco de sua história. Desde seu surgimento, o coletivo tem fortes relações com o PT e com outras organizações ligadas à esquerda. Depois da experiência com o $\mathrm{CR}, \mathrm{o}$ grupo passa por forte processo de radicalização, que se expressa na mudança de seu

\footnotetext{
${ }^{7}$ Desde o fim do segundo semestre de 2012, a Coordenadoria de Políticas para a Diversidade Sexual passou a dividir espaço na sede do CR, deixando de ocupar uma sala na prefeitura da cidade. Os gestores relataram que todos os coordenadores e centros ligados às coordenadorias existentes no município passaram a dividir a mesma sede por decisão do atual secretário
} 
nome: de Grupo de Ação pela Cidadania Homossexual passa a se denominar Grupo de Luta pela Diversidade Sexual.

Essa mudança, como afirmam os ativistas, está ligada à maneira como passaram a compreender o Estado a partir das relações estabelecidas com o executivo municipal. Tais relações remetem não só à participação no $\mathrm{OP}$, mas também à execução de projetos através de editais públicos. Contribui para essa modificação a aproximação com outros movimentos sociais como o Movimento Negro e o Passe Livre, tidos como mais contestadores. A partir dessas relações, passaram a compreender cidadania como uma categoria burguesa que previa aliança com o Estado. Em decorrência do processo de radicalização que culmina com a mudança do nome em 2008, o grupo passa a se compreender como anti-Estado, a categoria cidadania deixa de figurar em seu nome e ação é substituída por luta, visto que essa segunda categoria é, de acordo com os ativistas, mais característica de um movimento social (ZANoLI; FACCHINI, 2012).

\section{Tecendo reflexões}

Essa descrição do drama, que envolve a relação entre diferentes atores sociais no processo de formulação e implementação de uma política pública, ajuda a refletir sobre as relações do movimento social em questão e sua identidade institucional. Colabora, ainda, para a análise sobre os trânsitos e múltiplos pertencimentos institucionais que têm se tornado cada vez mais comuns no período pós-redemocratização no Brasil, com a ampliação da participação do movimento social na construção de políticas públicas (FACCHINI, 2009).

Nesse drama, não só os contornos do que é entendido como Estado e como movimento social são continuamente produzidos e negociados, como os próprios papéis de cada um desses atores são reelaborados. A partir de uma abordagem relacional e processual (STRATHERN, 1996), o olhar para a porosidade das fronteiras entre Estado e movimento social, verificada no campo, bem como para a constatação de "múltiplos pertencimentos", nos permitem problematizar análises que tomam tais atores como entidades discretas e homogêneas.

0 “trânsito de atores” pode ser observado através da trajetória de Lucas, quando deixa o Identidade, mantendo apenas o cargo de coordenador do CR. Análises sobre movimento LGBT chamam atenção para o crescente trânsito de atores no movimento LGBT brasileiro pós-redemocratização (FACCHINI, 2005; SIMÕES; FAC- 
CHINI, 2009; FACCHINI; FRANÇA, 2009). Entretanto, é importante ressaltar que esse fenômeno não é característico apenas das relações estabelecidas pelo movimento LGBT. Ativistas de outros movimentos, como os pelos direitos das crianças (GREGORI, 2000) e os ligados à periferia (FELTRAN, 2010), também passaram a oferecer quadros para a gestão pública.

Lucas nos permite contemplar não só o trânsito de atores, mas, também, os "múltiplos pertencimentos". Seu duplo pertencimento institucional foi mantido por algum tempo. Ainda que as tensões entre ele, enquanto coordenador, e os ativistas do grupo em que militava tenham acarretado na sua saída do mesmo, em outras circunstâncias, sua múltipla inserção institucional poderia, talvez, ter se mantido. Essa duplicidade se expressa, também, na pertença de ativistas a outras instituições que nem sempre são vistas como aliadas, como é o caso de partidos políticos, ou a academia.

Mariza Corrêa (1983), inspirada por Victor Turner (2009), lança mão da análise de momentos de crise, assassinatos e tentativas de assassinatos entre cônjuges, para compreender a construçãodo que chama de papéis sexuais ideais de homens e mulheres, além da maneira pela qual tais papéis são reforçados pelo judiciário brasileiro.

Segundo Turner, os momentos de crise possibilitam ao antropólogo acessar a estrutura social, a saber, a maneira como as relações entre pessoas e grupos de pessoas se estabelecem. Ora, a partir do drama aqui apresentado o mesmo pode ser feito. Ainda que em menor escala, os conflitos que o constituem evidenciam a construção processual de ideais a cada um dos atores envolvidos no processo. Isto é, como os atores atribuem papéis a si mesmos e aos outros nas relações que estabelecem, os produtos dessa atribuição são elaborados e transformados no interior de processos políticos e a partir dessas relações.

Strathern (1996a, 1996b) aponta para essa produção relacional de significado. Segundo ela, em uma rede, os pontos são produzidos através das relações que estabelecem consigo e com os outros. Assim sendo, os significados e papéis atribuídos a atores políticos seriam produzidos nessas relações.

O olhar para relações de conflito entre esses diversos atores nos permitiu contemplar os mecanismos de produção de significado dentro dessa rede. Isto é, as lutas simbólicas travadas entre cada um desses atores acerca de (a) categorias como 
política, ação, luta, movimento social e Estado; e (b) de papéis atribuídos por cada um deles a entidades como o movimento social e o Estado.

Essa produção relacional e processual de papéis e significados fica evidente em momentos de crise. Todos os momentos de crise tratados nesse artigo parecem evidenciar a maneira como os atores envolvidos no processo político em questão produzem as noções através das quais pensam sua ação política.

Um momento que pode ser trazido como exemplo é o episódio que leva à fundação do Identidade (ZANOLI; FACCHINI, 2012). Tal acontecimento evidencia concepções antagônicas no que diz respeito ao que se compreende como movimento social e ao significado de política. Para a parcela do grupo Expressão que veio a fundar o Identidade, um movimento social deveria se preocupar mais com política, e menos com festividade, diferentemente do que aconteceria no Expressão. A partir dessa tensão, os fundadores do Identidade passaram a forjar o que seria política e qual seria o papel de um movimento social, categorias que continuam a se modificar conforme as relações com o Estado são estabelecidas.

Ao longo do tempo, esse tipo de ação coletiva é crescentemente significado pelos integrantes do Identidade por uma característica: a de contestar e cobrar o/ do Estado. Do mesmo modo, o papel atribuído ao Estado, a partir das relações que o Identidade estabeleceu não só com o próprio Estado, mas com os demais atores presentes em sua rede de relações, também se modificou. Se, em um primeiro momento, o Estado foi visto como possível parceiro, as tensões causadas pelas relações entre os ativistas, a SAJ e o CR fizeram com que passasse a ser visto como instituição passível de suspeitas. A maneira como os ativistas avaliaram as relações com o Estado criou condições não apenas para que o grupo se colocasse como anti-Estado, mas para o próprio processo de radicalização pelo qual passou grupo.

Além disso, é a partir das relações entre cada um dos atores presentes no campo de ativismo do movimento LGBT de Campinas que os integrantes compreendem categorias como política, luta, ação, Estado e movimento social e a própria homossexualidade e as diversas formas identitárias, ou não, que ela pode assumir. A produção de alianças entre esses atores, assim como as disputas, têm como base a atribuição de significado. Os atores que conferem sentidos de modo semelhante tendem a estabelecer alianças, colaborando, desse modo, para a cristalização de determinados significados em detrimento de outros. 


\section{Considerações finais}

Neste artigo, procurei situar os atores sociais envolvidos no processo de proposição e de implementação do Centro de Referência GLTTB de Campinas (atual Centro de Referência Especializado em Assistência Social - CREAS LGBT de Campinas), bem como as relações que se estabelecem entre eles na trama que se forma em torno das políticas para LGBT do município. Tal trama que, por sua vez, é permeada por disputas e alianças. 0 que possibilita, por fim, afirmar que não só as fronteiras do que se compreende como movimento social e Estado, como as categorias acionadas para se referir à ação política e aos atores sociais, são produtos das relações que cada um dos atores estabelece com os demais no campo político. No limite, as categorias e sentidos que permitem pensar os atores e ações políticas são construídos e reconstruídos coletivamente o tempo todo pelos próprios atores em relação no interior de processos políticos.

\section{Referências}

CÂmara, C. (2002). Cidadania e orientação sexual: a trajetória do grupo Triângulo Rosa. Rio de Janeiro, Academia Avançada.

CoRrÊA, M. (1983). Morte em família: representações jurídicas de papéis sexuais. Rio de Janeiro, Edições Graal.

FELtRAN, G. S. (2010). "Margens da política, fronteiras da violência: uma ação coletiva das periferias de São Paulo". Lua Nova, São Paulo, 79: 201-233.

FACCHINI, R. (2009). "Entre compassos e descompassos: um olhar para o campo e para a arena do movimento LGBT brasileiro". Bagoas, v. 1, p. 131-158.

. (2008). Entre umas e outras: mulheres, (homo)sexualidades e diferença na cidade de São Paulo. (Tese) Doutorado - Instituto de Filosofia e Ciências Humanas, Universidade Estadual de Campinas, Campinas.

(2005). Sopa de letrinhas? Movimento homossexual e produção de identidades coletivas nos anos 90 . Rio de Janeiro, Garamond.

FACCHINI, R.; FrAnÇA, I. L. (2009). “De cores e matizes: sujeitos, conexões e desafios no Movimento LGBT brasileiro". Sexualidad, salud y sociedad - Revista latinoamericana. n. 3, p. 55-81.

FranÇA, I. L. (2012a). Consumindo lugares, consumindo nos lugares: homossexualidade, consumo e subjetividades na cidade de São Paulo. Rio de Janeiro, Ed. UERJ. 
. (2012b). "Sexualidade e política: uma abordagem a partir do mercado e do consumo". Bagoas, v. 6, n. 7, jan./jun.

GREgoRI, M. F. (2000). Viração - experiências de meninos nas ruas. São Paulo, Companhia das Letras.

MACRAE, E.(1990). A construção da igualdade: identidade sexual e política no Brasil da abertura. Campinas, Ed. Unicamp.

Simões, J. A.; FACCHINI, R. (2009). Na trilha do arco-íris: do homossexual ao movimento LGBT. São Paulo, Editora Fundação Perseu Abramo.

Strathern, M. (1996a). "Cutting the network". The Journal of the Royal Anthropological Institute. v. 2. n. 3.

. (2006). O Gênero da dádiva: problemas com as mulheres e problemas com a sociedade na Melanésia. Campinas, Ed. Unicamp.

. (1989). "The concept of society is theoretically obsolete: for the motion (1)". In: INGOLD, T, (Org.). Key debates in anthropology. Londres, Routledge.

TURNER, V. W. (2009 [1969]). The ritual process: structure and anti-structure. Nova Brunswick, Aldine.

ZANOLI, V.; FACCHINI, R. (2012). “Conexões, atores, políticas sexuais e cidade: uma reflexão a partir da trajetória do grupo Identidade de Campinas/SP". Ponto Urbe, n. 10, ano 6, Julho.

Recebido em dezembro/2012

Aprovado em fevereiro/2013 